\title{
The association of an adenine insertion variant in the 5' UTR of the endothelin-1 gene with hypertension and orthostatic hypotension
}

\author{
Xiao-han Fan', Hu Wang ${ }^{2}$, Ling-gen Gao', Kai Sun², Xiang-liang Zhou¹, Ru-tai Hui ${ }^{1,2}$
}

1Department of Cardiology, Cardiovascular Institute and FuWai Hospital, Chinese Academy of Medical Sciences and Peking Union Medical College, Beijing, China

2Sino-German Laboratory for Molecular Medicine and Key Laboratory for Clinical Cardiovascular Genetics, Ministry of Education, Cardiovascular Institute and FuWai Hospital, Chinese Academy of Medical Sciences and Peking Union Medical College, Beijing, China

Submitted: 28 April 2011

Accepted: 7 January 2012

Arch Med Sci 2012; 8, 2: 219-226

DOI: $10.5114 /$ aoms.2012.28548

Copyright $\odot 2012$ Termedia \& Banach

\section{Abstract}

Introduction: An adenine insertion polymorphism in the 5 ' untranslated region of the endothelin-1 gene is functional and increases the expression of endothelin mRNA and protein in the insertion homozygote. In the present study we hypothesized that this functional polymorphism might be associated with hypertension and/or orthostatic hypotension.

Material and methods: The adenine insertion polymorphism was genotyped in 381 untreated hypertensive patients and 298 normotensive subjects, all of whom underwent an upright posture study for orthostatic blood pressure measurements. Orthostatic hypotension was defined as a drop in blood pressure of 20/10 $\mathrm{mm} \mathrm{Hg}$ or more within 3 min of assuming the upright posture.

Results: The allele frequency of the adenine insertion was similar in hypertensive and normotensive subjects ( $15.2 \%$ vs. $15.3 \%, p>0.05)$. After adjustment for age, sex and body mass index, blood pressure levels did not differ significantly among the genotypes in both hypertensives and normotensives. No associations were found between the distribution of the adenine insertion genotypes and the risk of orthostatic hypotension in both hypertensive patients and normotensive subjects even after adjustment for demographic parameters and supine systolic or diastolic blood pressure. Neither hypertensive nor normotensive subjects showed significant differences in orthostatic systolic or diastolic blood pressure changes among the genotype groups (all $p>0.05$ ).

Conclusions: We concluded that the functional adenine insertion polymorphism in the endothelin-1 gene is not associated with either hypertension or orthostatic hypotension risk in Chinese.

Key words: polymorphism, genotype, blood pressure.

\section{Introduction}

Endothelin-1 (ET-1) is one of the most important vasoconstrictor peptides in the human vascular system [1], where it appears to play a fundamental role in the maintenance of basal vasomotor tone [2, 3]. The biological effects of ET-1 are mediated through the activation of two known ET-1 receptors, ET-A and ET-B $[4,5]$. The ET-1 is thought to be involved in blood pressure (BP) regulation because of the elevated plasma ET-1 levels

\author{
Corresponding author: \\ Ru-tai Hui MD, PhD \\ Department of Cardiology \\ Cardiovascular Institute \\ and FuWai Hospital \\ Chinese Academy \\ of Medical Sciences \\ and Peking Union \\ Medical College \\ 167 Bei Li Shi Road \\ Beijing 100037, China \\ Phone: +86 (10) 68333902 \\ Fax: + 86 (10) 68331730 \\ E-mail: huirutai@sglab.org
}


that have been observed in some hypertensive patients [6] and because of the reported elevated $\mathrm{BP}$ in mice heterozygous for a knockout of the ET-1 gene (Edn1) [7]. In mice, the knockout of collecting duct ET-1 or the combined ET-A and ET-B receptors also caused hypertension on both a normal and high sodium diet $[8,9]$. In normal human subjects, upright tilt did not change arterial pressure but it did increase the plasma concentrations of ET-1 and vasopressin $[10,11]$. The increase in plasma ET-1 concentration was impaired in patients with autonomic failure [11] as well as in patients with tilt-induced syncope [12]. Therefore, the EDN1 gene is a logical candidate to play a role in hypertension and orthostatic hypotension $(\mathrm{OH})$.

The ET-1 is produced in endothelial cells and is predominantly secreted toward the adjacent vascular smooth muscle cells, supporting the notion that endothelins (ETs) are autocrine/paracrine agents rather than circulating hormones [13]. Elevated ET-1 levels have been found in some but not all studies of patients with essential hypertension $[14,15]$. Furthermore, increased ET-1 levels are neither related to BP in hypertensive patients nor do they induce hypertension in patients with diabetes [15]. EDN1 mRNA is upregulated by inflammatory factors and downregulated by nitric oxide (NO), prostacyclin (PGI2), hypoxia and shear stress [16]. An adenine insertion, located in the $5^{\prime}$ untranslated region (UTR) 138 bp downstream of the transcription start site, is functional and regulates the expression of EDN1 causing increased mRNA expression and endothelin protein expression in insertion homozygotes [17]. This polymorphism has been associated with orthostatic intolerance [18] and diastolic BP level in white people [19]. However, previous studies have produced inconsistent results for the association of hypertension with EDN1 polymorphisms [20, 21] and few data are available on the association of the adenine insertion polymorphism with $\mathrm{OH}$. We therefore hypothesized that the adenine insertion variant of EDN1 may be associated with increased risk of hypertension and $\mathrm{OH}$ in Chinese people. We tested our hypothesis in 381 untreated hypertensive patients and 298 normotensive subjects.

\section{Material and methods}

\section{Study population}

For this study, we recruited 381 unrelated hypertensive patients and 298 normotensive subjects from Xinyang in Henan Province. To exclude the effect of antihypertensive drugs on orthostatic BP regulation, only untreated patients were included in the study. Hypertensive patients were defined as untreated if they were newly diagnosed with hypertension (systolic BP (SBP)/diastolic BP (DBP) $\geq 160 / 95 \mathrm{~mm} \mathrm{Hg}$ on 3 occasions within 2 months) and/or if they had been diagnosed as hypertensive (SBP/DBP $\geq 140 / 90 \mathrm{~mm} \mathrm{Hg}$ ) in the past but had not received any antihypertensive drugs for at least 8 weeks prior to the study. Subjects with systolic and/or diastolic BP levels $<130 / 85 \mathrm{~mm} \mathrm{Hg}$ and no family history of hypertension were recruited as normotensive subjects. Subjects were excluded from the study if they had any known diseases, including heart failure, secondary hypertension, Parkinson disease, diabetes mellitus, severe debilitating chronic illness (cancer, renal or hepatic diseases), and any history of coronary heart disease and stroke, and/or if they were currently receiving antidepressant medications. All subjects underwent an upright posture study for orthostatic BP measurements. This study was reviewed and approved by the ethical committees of FuWai Hospital and local hospitals, and informed consent was obtained from each subject before they were recruited.

\section{Data collection}

Each eligible participant was interviewed in a community clinic. Anthropometric measurements, height $(\mathrm{m})$ and weight $(\mathrm{kg})$, and waist and hip circumference (measured at the umbilicus and the widest point, respectively), were obtained by trained researchers. All subjects underwent a standard 12-lead ECG. Overnight fasting blood was drawn for assays of fasting blood glucose, blood lipids [total cholesterol (TC), triglycerides (TG), high-density lipoprotein cholesterol (HDL-C), low-density lipoprotein cholesterol (LDL-C)], serum uric acid and creatinine levels by the core laboratory at FuWai Hospital. Medical history and cigarette smoking and alcohol consumption status were obtained using a standardized questionnaire. Obesity was defined according to World Health Organization criteria as body mass index (BMI) $\geq 30.0 \mathrm{~kg} / \mathrm{m}^{2}$. Metabolic syndrome (MS) was determined according to the International Diabetes Federation (IDF) criteria of 2005. Dyslipidemia was diagnosed as any one of the following: TG > $200 \mathrm{mg} / \mathrm{dl}$; TC $\geq 240 \mathrm{mg} / \mathrm{dl}$; LDL-C $\geq 160 \mathrm{mg} / \mathrm{dl}$; or HDL-C $<40 \mathrm{mg} / \mathrm{dl}$, according to the Adult Treatment Panel III guideline [22].

Sitting BP was measured by a trained nurse or physician with a standardized mercury sphygmomanometer and appropriate cuff sizes (regular, large, or thigh) fitted to the subject's right arm. Three readings were recorded in a sitting position at least $30 \mathrm{~s}$ apart after more than 5 min of rest, and three readings on average were analyzed. All BP investigators had to complete a training program on the preparation of study subjects for measuring BP, selection of correct cuff size, and standard BP measurement technique according to a common protocol adapted from procedures recommended by the American Heart Association [23]. 
Supine and standing BP were recorded with a mercury sphygmomanometer following a standardized protocol by a trained physician or nurse. After a 15-min ECG examination with the participant lying on an examination table, three supine measurements of BP and heart rate were recorded at approximately $>30$ s intervals by a trained professional. Participants were then asked to rise from the supine position with the entire forearm relaxed and supported at heart level on an adjustable table, and standing measurements were taken at $30 \mathrm{~s}$ and 2 min. $\mathrm{OH}$ was defined as a decline in SBP of at least $20 \mathrm{~mm} \mathrm{Hg}$ and/or a decline in DBP of at least $10 \mathrm{~mm} \mathrm{Hg}$ either $30 \mathrm{~s}$ or $2 \mathrm{~min}$ after shifting from a supine to an upright posture [24].

\section{Genotyping}

Genomic DNA was isolated from peripheral leukocytes. The adenine insertion/deletion polymorphism (rs10478694, also described as 4A/3A polymorphism) $138 \mathrm{bp}$ downstream of the transcription start site in the 5' UTR of EDN1 was detected by standard polymerase chain reaction (PCR)restriction fragment length polymorphism (RFLP) analysis, gel electrophoresis, and ethidium bromide staining. All aspects of the DNA source, preparation and genotyping were controlled using the paradigms of blindness and randomization. The reproducibility of the genotyping was confirmed by bidirectional sequencing in 100 randomly selected samples, and was found to be $100 \%$. The primer sequences used were as follows: forward, 5'-AGGCGCTGCCTTTTCTCCCCGTTTAA-3' and reverse, 5'-AGCTCCTTGGCAAGCCACAAACAGCA-3'. The resultant PCR products were digested using the restriction enzyme Dral (New England Biolabs). The genotypes were 3A/3A, 221 bp; 4A/3A, 197 bp, 221 bp and $24 \mathrm{bp}$; and 4A/4A, $197 \mathrm{bp}$ and $24 \mathrm{bp}$.

\section{Statistical analysis}

All of the data were analyzed with SPSS statistical software (version 13.0; SPSS USA Inc). Quantitative variables were compared using one-way analysis of variance (ANOVA), and Tukey's test or $t$-test was used for comparison of the mean values for pairs of groups. The $\chi^{2}$ test was used for qualitative variables, genotype/allele frequencies, and for the Hardy-Weinberg equilibrium of polymorphisms. Stepwise multiple logistic regression analysis was used to assess the contribution of genotypes to hypertension or $\mathrm{OH}$ with adjustment for age, BMI, supine BP levels, heart rates, fasting blood glucose and dyslipidemia. The orthostatic BP changes among genotypes were compared first by ANOVA or t test, and then by a general linear model with adjustment for age, sex, BMI, and supine BP levels. A two-tailed $p$ value of $<0.05$ was consid- ered significant. Assuming an additive model, the study had more than $80 \%$ statistical power to detect an association (at $p=0.05$ ) with an odds ratio (OR) of $1.5-1.75$ for alleles at $10-20 \%$ frequency, which indicated a low probability of obtaining a false negative result.

\section{Results}

\section{The association of the EDN1 3A/4A} polymorphism with hypertension risk

Table I summarizes the characteristics of hypertensive patients and normotensive subjects. As expected, SBP, DBP and most of the other characteristics were higher in hypertensive patients than in normotensive subjects. The EDN1 3A/4A genotypes were in Hardy-Weinberg equilibrium in the hypertensive patients $\left(\chi^{2}=2.74, p=0.10\right)$ and in the normotensive subjects $\left(\chi^{2}=3.29, p=0.07\right)$. However, no significant differences were found in the genotype/allele frequencies of the $3 \mathrm{~A} / 4 \mathrm{~A}$ polymorphism between hypertensive and normotensive subjects in either the additive, dominant or recessive models (Table II). After adjustment for age, BMI, heart rates, fasting blood glucose, plasma lipids and other conventional risk factors, the association of hypertension with BMI and heart rates remained statistically significant but the adenine insertion polymorphism was still not found to be associated with hypertension risk.

When the systolic and diastolic BP levels were analyzed separately in hypertensive and nor-

Table I. Clinical characteristics of hypertensive patients and normotensive controls

\begin{tabular}{|c|c|c|c|}
\hline Characteristic & $\begin{array}{c}\text { Normotensive } \\
\text { controls } \\
(n=298)\end{array}$ & $\begin{array}{c}\text { Hypertensive } \\
\text { patients } \\
(n=381)\end{array}$ & Value of $p$ \\
\hline Gender, M/F & 107/191 & $133 / 248$ & NS \\
\hline Age [year] & $53.1 \pm 10.5$ & $55.3 \pm 8.2$ & $<0.05$ \\
\hline $\mathrm{BMI}\left[\mathrm{kg} / \mathrm{m}^{2}\right]$ & $24.3 \pm 3.3$ & $25.9 \pm 3.5$ & $<0.05$ \\
\hline $\mathrm{SBP}[\mathrm{mm} \mathrm{Hg}]$ & $124.0 \pm 11.8$ & $160.2 \pm 22.8$ & $<0.05$ \\
\hline $\mathrm{DBP}[\mathrm{mm} \mathrm{Hg}]$ & $80.5 \pm 6.9$ & $98.5 \pm 11.2$ & $<0.05$ \\
\hline $\begin{array}{l}\text { Heart rate } \\
{[\mathrm{bpm}]}\end{array}$ & $73.8 \pm 12.2$ & $69.7 \pm 11.2$ & $<0.05$ \\
\hline $\mathrm{HDL}-\mathrm{C}[\mathrm{mmol} / \mathrm{l}]$ & 1] $1.50 \pm 0.31$ & $1.57 \pm 0.34$ & $<0.05$ \\
\hline LDL-C [mmol/ll] & $2.65 \pm 0.81$ & $3.10 \pm 0.88$ & $<0.05$ \\
\hline $\mathrm{TC}[\mathrm{mmol} / \mathrm{l}]$ & $4.97 \pm 1.02$ & $5.49 \pm 1.15$ & $<0.05$ \\
\hline $\mathrm{FBG}[\mathrm{mmol} / \mathrm{l}]$ & $4.97 \pm 1.69$ & $5.50 \pm 1.62$ & $<0.05$ \\
\hline Smoking [\%] & 20.1 & 16.5 & NS \\
\hline Drinking [\%] & 21.8 & 21.0 & NS \\
\hline
\end{tabular}

$B M I$ - body mass index, SBP - systolic blood pressure, DBP - diastolic blood pressure, HDL-C - high-density lipoprotein cholesterol, LDL-C - low-density lipoprotein cholesterol, TC - total cholesterol, FBG - fasting blood glucose, smoking, current and past cigarette smoking; drinking, current and past alcohol drinking 
Table II. ET1 3A/4A genotypes in hypertensive and normotensive subjects

\begin{tabular}{|c|c|c|c|c|c|c|c|c|c|c|}
\hline \multirow[t]{2}{*}{ Subject } & \multirow[t]{2}{*}{$N$} & \multicolumn{4}{|c|}{ ET1 genotype frequencies $n(\%)$} & \multicolumn{3}{|c|}{ Allele frequencies $n(\%)$} & \multicolumn{2}{|c|}{ Adjusted OR (95\% Cl) } \\
\hline & & $3 A / 3 A$ & $3 \mathrm{~A} / 4 \mathrm{~A}$ & $4 \mathrm{~A} / 4 \mathrm{~A}$ & $p(\mathrm{~d} / \mathrm{r})^{*}$ & $3 \mathrm{~A}$ & $4 \mathrm{~A}$ & $p$ & $\begin{array}{c}\text { Allele } \\
(3 \mathrm{~A} \leftrightarrow 4 \mathrm{~A})\end{array}$ & $\begin{array}{c}\text { Dominant } \\
\text { model } \\
(3 \mathrm{~A} / 4 \mathrm{~A}+ \\
+4 \mathrm{~A} / 4 \mathrm{~A} \leftrightarrow \\
\leftrightarrow 3 \mathrm{~A} / 3 \mathrm{~A})\end{array}$ \\
\hline Hypertensives & 381 & $278(73.0)$ & $90(23.6)$ & $13(3.4)$ & 0.97 & $646(84.8)$ & $116(15.2)$ & \multirow[t]{2}{*}{0.98} & 1.00 & 0.99 \\
\hline Normotensives & 298 & $218(73.2)$ & $69(23.2)$ & $11(3.7)$ & $(0.95 / 0.84)$ & $505(84.7)$ & $91(15.3)$ & & $(0.75-1.35)$ & $(0.78-1.29)$ \\
\hline
\end{tabular}

${ }^{*}(d / r) p$ values under dominant/recessive models

A



$\square 3 \mathrm{~A} / 3 \mathrm{~A}$
B

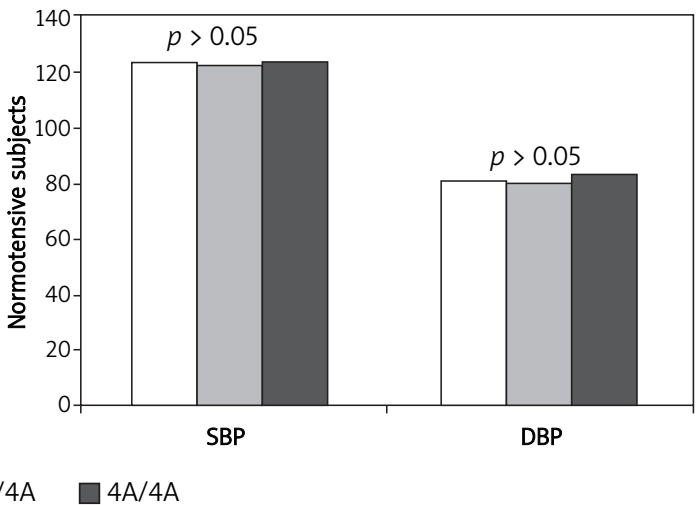

Figure 1. Mean SBP and DBP levels in individuals carrying EDN1 3A/4A genotypes. Values were adjusted for age, sex and body mass index using a general linear model. A - Hypertensive patients. B - Normotensive subjects

motensive subjects, the results showed that the hypertensive and normotensive subjects carrying different 3A/4A genotypes had similar systolic and diastolic BP levels even after adjustment for age, sex, and body mass index (Figure 1).

\section{The association of the EDN1 3A/4A polymorphism with $\mathrm{OH}$ in hypertensive and normotensive subjects}

Most of the measured characteristics were comparable between the patients with and without $\mathrm{OH}$ except that normotensive subjects with $\mathrm{OH}$ had significantly lower SBP and DBP than those without $\mathrm{OH}$ (Table III). Both hypertensives and normotensives exhibited a similar pattern of BP response to posture change: higher supine SBP or DBP levels and lower standing SBP or DBP levels in all subjects with $\mathrm{OH}$ compared to the levels in subjects without $\mathrm{OH}$.

The results in Table IV show that no significant differences were found in the genotype/allele frequencies of the $3 \mathrm{~A} / 4 \mathrm{~A}$ polymorphism between subjects with and without $\mathrm{OH}$ in both hypertensives and normotensives in the additive, dominant and recessive models. After adjustment for supine SBP or DBP levels, heart rates, and conventional risk factors using a stepwise multiple logistic regression model, the contribution of the EDN1 adenine insertion allele to the presence of $\mathrm{OH}$ remained statistically not significant in the hypertensive and normotensive subjects. A statistically significant association was found between $\mathrm{OH}$ and supine systolic BP in hypertensive patients (OR 1.03, 95\% Cl $1.00-1.06, p=0.049$ ) and in normotensive subjects (OR 1.04, 95\% Cl 1.02-1.06, $p<0.001$ ).

We then analyzed the associations between the EDN1 3A/4A polymorphism and orthostatic SBP/DBP changes at $30 \mathrm{~s}$ and 2 min after standing as well as supine SBP/DBP in both hypertensive and normotensive subjects; no association was found even after adjustment for age, sex, BMI and supine SBP or DBP using a general linear model (Table V).

\section{Discussion}

In the present study, we investigated the association of the adenine insertion polymorphism in the 5' UTR of the EDN1 gene with hypertension and $\mathrm{OH}$ risk. After adjustment for age, sex, $\mathrm{BMI}$, and the other conventional risk factors that were measured, the EDN1 adenine insertion polymorphism was found not to be associated with hypertension risk or with systolic and diastolic BP levels. In both hypertensive and normotensive subjects, no asso- 
Table III. Clinical characteristics of hypertensive and normotensive subjects with and without $\mathrm{OH}$

\begin{tabular}{|c|c|c|c|c|}
\hline \multirow[t]{2}{*}{ Characteristics } & \multicolumn{2}{|c|}{ Hypertensive patients } & \multicolumn{2}{|c|}{ Normotensive subjects } \\
\hline & With $\mathrm{OH}$ & Without $\mathrm{OH}$ & With $\mathrm{OH}$ & Without $\mathrm{OH}$ \\
\hline$N$ & 78 & 303 & 72 & 226 \\
\hline Age [years] & $55.6 \pm 7.9$ & $55.0 \pm 8.7$ & $51.3 \pm 10.3$ & $53.5 \pm 10.9$ \\
\hline$>60$ years, $\%(n)$ & $31.0(24)$ & $27.1(82)$ & $20.8(15)$ & $27.9(63)$ \\
\hline Male, \% (n) & $32.1(25)$ & $36.0(109)$ & $37.5(27)$ & $41.2(93)$ \\
\hline BMI $\left[\mathrm{kg} / \mathrm{m}^{2}\right]$ & $26.0 \pm 3.6$ & $25.9 \pm 3.4$ & $24.6 \pm 3.5$ & $24.2 \pm 3.2$ \\
\hline Seated SBP [mm Hg] & $162.3 \pm 20.0$ & $160.6 \pm 23.1$ & $121.4 \pm 12.7$ & $124.8 \pm 11.3^{*}$ \\
\hline Seated DBP [mm Hg] & $98.6 \pm 10.9$ & $98.4 \pm 11.7$ & $78.4 \pm 7.8$ & $81.1 \pm 7.5^{\star}$ \\
\hline $\mathrm{HR}$ [bpm] & $75.4 \pm 12.5$ & $73.0 \pm 12.0$ & $69.1 \pm 9.3$ & $69.8 \pm 11.4$ \\
\hline Dyslipidemia, \% (n) & $26.9(21)$ & $32.0(97)$ & $23.6(17)$ & $27.0(61)$ \\
\hline MS, \% (n) & $21.8(17)$ & $26.7(81)$ & $12.5(9)$ & $12.4(28)$ \\
\hline Obesity, \% (n) & $16.7(13)$ & $11.0(33)$ & $5.6(4)$ & 4.9 (11) \\
\hline Supine SBP [mm Hg] & $162.9 \pm 24.8$ & $153.6 \pm 24.7^{\star}$ & $130.0 \pm 15.3$ & $124.5 \pm 14.8^{*}$ \\
\hline Supine DBP [mm Hg] & $99.2 \pm 15.6$ & $91.9 \pm 12.3^{*}$ & $83.4 \pm 10.0$ & $79.2 \pm 8.7^{\star}$ \\
\hline Standing SBP at $30 \mathrm{~s}[\mathrm{~mm} \mathrm{Hg}]$ & $146.5 \pm 22.3$ & $153.2 \pm 24.8^{*}$ & $113.4 \pm 15.3$ & $124.2 \pm 14.7^{\star}$ \\
\hline Standing DBP at $30 \mathrm{~s}$ [mm Hg] & $91.2 \pm 12.9$ & $96.9 \pm 12.7^{\star}$ & $73.7 \pm 10.1$ & $81.8 \pm 9.8^{*}$ \\
\hline Standing SBP at $2 \mathrm{~min}[\mathrm{~mm} \mathrm{Hg}]$ & $146.3 \pm 22.1$ & $155.4 \pm 24.6^{*}$ & $114.3 \pm 15.7$ & $125.3 \pm 14.8^{*}$ \\
\hline Standing DBP at $2 \min [\mathrm{mm} \mathrm{Hg}]$ & $93.7 \pm 12.7$ & $98.5 \pm 13.9^{*}$ & $74.6 \pm 8.6$ & $83.1 \pm 9.9^{\star}$ \\
\hline
\end{tabular}

$\mathrm{OH}$ - orthostatic hypotension, BMI - body mass index, SBP-systolic blood pressure, DBP-diastolic blood pressure, MS - metabolic syndrome; ${ }^{*} p<0.05$ patients with $\mathrm{OH}$ vs. patients without $\mathrm{OH}$

Table IV. Prevalence of OH among ET1 genotypes in hypertensive and normotensive subjects

\begin{tabular}{|c|c|c|c|c|c|c|c|c|}
\hline \multirow[t]{2}{*}{ Subject } & \multirow[t]{2}{*}{$N$} & \multicolumn{4}{|c|}{ Genotype frequencies $n(\%)$} & \multicolumn{3}{|c|}{ Allele frequencies $n(\%)$} \\
\hline & & $3 A / 3 A$ & $3 \mathrm{~A} / 4 \mathrm{~A}$ & $4 \mathrm{~A} / 4 \mathrm{~A}$ & $p(\mathrm{r} / \mathrm{d})^{*}$ & $3 \mathrm{~A}$ & $4 \mathrm{~A}$ & $p$ \\
\hline \multicolumn{9}{|c|}{ Hypertensives } \\
\hline $\mathrm{OH}$ & 78 & $59(75.6)$ & $15(19.2)$ & $4(5.1)$ & \multirow[t]{2}{*}{$0.42(0.55 / 0.35)$} & $133(85.3)$ & $23(14.7)$ & \multirow[t]{2}{*}{0.85} \\
\hline $\mathrm{Non} \mathrm{OH}$ & 303 & $219(72.3)$ & $75(24.8)$ & $9(3.0)$ & & $513(84.7)$ & $93(15.3)$ & \\
\hline \multicolumn{9}{|c|}{ Normotensives } \\
\hline $\mathrm{OH}$ & 72 & $54(75.0)$ & $16(22.2)$ & $2(2.8)$ & \multirow[t]{2}{*}{$0.86(0.68 / 0.64)$} & $124(86.1)$ & $20(13.9)$ & \multirow[t]{2}{*}{0.60} \\
\hline Non $\mathrm{OH}$ & 226 & $164(72.6)$ & $53(23.5)$ & $9(4.0)$ & & $381(84.3)$ & $71(15.7)$ & \\
\hline
\end{tabular}

*(d/r) $p$ values under dominant/recessive models

ciation was found between the EDN1 3A/4A polymorphism and $\mathrm{OH}$ or between the EDN1 3A/4A polymorphism and orthostatic SBP/DBP changes at $30 \mathrm{~s}$ and at $2 \mathrm{~min}$ after standing.

The ET-1 is a powerful controller of vasomotor tone. A recent study reported normal BP in mice systemically heterozygous for the ET-1 null allele and decreased BP in endothelial cell-specific ET-1 knockout mice [25]. It has been found that increased ET-1 activity could impair endotheliumdependent vasodilator function in hypertensive patients [26]. These results indicated that ET-1 played an important role in the regulation of BP and suggested that the functional EDN1 genetic variation may contribute to the development and varia- tion of BP. The EDN1 3A/4A polymorphism was found to be of functional importance for ET-1 expression [17]. It has also been associated with smoking in hypertensive patients and with less risk for chronic heart failure [27, 28]. However, the association of the $3 \mathrm{~A} / 4 \mathrm{~A}$ polymorphism with hypertension needs to be investigated further because the results from the present study and from previous studies found no significant difference in the allele or genotype frequency between the hypertensive patients and the normotensive controls [21, 28, 29]. In a genome-wide association study, a few loci (chromosome regions) associated with BP at a genome-wide level of statistical significance have been reported $[30,31]$. However, no genetic vari- 
Table V. Orthostatic BP changes among genotypes in hypertensive and normotensive subjects

\begin{tabular}{|lccccc|}
\hline Orthostatic BP change & \multicolumn{3}{c}{ Genotypes } & \multirow{2}{*}{ Value of $p$} & Adjusted $p$ \\
\cline { 2 - 4 } & 3A/3A & 3A/4A & 4A/4A & \\
\hline Hypertensive patients & $n=278$ & $n=90$ & $n=13$ & \\
\hline Supine SBP & $153.6 \pm 23.9$ & $156.3 \pm 27.8$ & $160.7 \pm 26.5$ & 0.86 & 0.53 \\
\hline Supine DBP & $93.1 \pm 13.4$ & $95.3 \pm 14.5$ & $94.4 \pm 11.6$ & 0.96 & 0.49 \\
\hline$\Delta$ SBPO [mm Hg] & $-3.6 \pm 12.4$ & $-3.0 \pm 12.3$ & $-1.5 \pm 13.4$ & 0.97 & 0.84 \\
\hline$\Delta$ DBPO [mm Hg] & $2.3 \pm 8.4$ & $2.1 \pm 8.3$ & $7.9 \pm 10.3$ & 0.44 & 0.15 \\
\hline$\Delta$ SBP2 [mm Hg] & $-2.0 \pm 12.2$ & $-2.2 \pm 14.0$ & $-0.4 \pm 14.1$ & 0.73 & 0.91 \\
\hline$\Delta$ DBP2 [mm Hg] & $4.0 \pm 9.7$ & $4.5 \pm 9.6$ & $7.0 \pm 10.5$ & 0.95 & 0.63 \\
\hline Normotensive subjects & $n=218$ & $n=69$ & $n=11$ & & \\
\hline Supine SBP & $125.7 \pm 15.2$ & $126.3 \pm 15.7$ & $122.1 \pm 9.4$ & 0.40 & 0.70 \\
\hline Supine DBP & $79.9 \pm 8.9$ & $80.3 \pm 7.2$ & $82.5 \pm 6.9$ & 0.93 & 0.68 \\
\hline$\Delta$ SBPO [mm Hg] & $-3.4 \pm 12.6$ & $-4.3 \pm 12.9$ & $-4.0 \pm 8.8$ & 0.55 & 0.89 \\
\hline$\Delta$ DBP0 [mm Hg] & $0.1 \pm 8.7$ & $-0.8 \pm 8.3$ & $-0.4 \pm 9.5$ & 0.33 & 0.82 \\
\hline$\Delta$ SBP2 [mm Hg] & $-3.0 \pm 12.3$ & $-3.8 \pm 12.4$ & $-3.0 \pm 12.8$ & 0.63 & 0.90 \\
\hline$\Delta$ DBP2 [mm Hg] & $1.1 \pm 8.3$ & $0.8 \pm 8.6$ & $0.8 \pm 9.9$ & 0.44 & 0.96 \\
\hline
\end{tabular}

$S B P$ - systolic blood pressure, $D B P$ - diastolic blood pressure, $\triangle S B P O-S B P$ changes at 0 min after standing, $\triangle S B P 2-S B P$ changes at 2 min after standing, $\triangle D B P O-D B P$ changes at 0 min after standing, $\triangle D B P 2-D B P$ changes at or 2 min after standing; $p$ value indicates comparisons between the genotypes; adjusted $p$ value - $p$ value adjusted for age, sex, body mass index and supine SBP or DBP using a general linear model

ants (including the $3 \mathrm{~A} / 4 \mathrm{~A}$ polymorphism) in EDN1 have been reported to be linked with these loci.

$\mathrm{OH}$ has been associated with hypertension, diabetes mellitus (DM), age, $\mathrm{BMI}$ and a number of drugs [32-34]. The most important compensatory mechanism for short-term orthostatic stress is the influence of the autonomic nervous system on peripheral vascular resistance, heart rate and contractility, and muscular activity. It has been shown that genes on chromosome $18 \mathrm{q}$ may be responsible for $\mathrm{OH}[35$, 36]. The NEDD4L gene is located just within the locus proximal to the $\mathrm{OH}$ markers on 18q [37] and a functional polymorphism of NEDD $4 L$ has been associated with $\mathrm{OH}$ [38]. $\mathrm{OH}$ has also been associated with the $\mathrm{G}$ protein $\alpha$-subunit (GNAS1) T131C polymorphism and the $G$ protein $\beta$ subunit (GNB3) C825T polymorphism [39]; these $G$ protein subunits are components of the sympathetic nervous system. In contrast, no associations have been reported between $\mathrm{OH}$ and polymorphisms in genes encoding the main components of the traditional RAS pathway [39, 40]. No data associating EDN1 polymorphisms with $\mathrm{OH}$ are available. A previous study reported a protective effect of the EDN1 adenine insertion variant for orthostatic intolerance, defined as an increase of at least 30 beats per minute in heart rate during upright posture and/or plasma norepinephrine concentrations $>600 \mathrm{pg} / \mathrm{ml}$ after $30 \mathrm{~min}$ of upright posture (or at the maximal standing tolerance time), and/or the presence of orthostatic symptoms including dizziness, lightheadedness, and blurred vision [18]. In contrast, a recent study showed that the EDN1 adenine insertion variant was associated with increased risk of tilt test-induced vasovagal syncope [41]. In the present study, we found no association between the $3 \mathrm{~A} / 4 \mathrm{~A}$ polymorphism and $\mathrm{OH}$, consistent with a previous study that found no association between the adenine insertion variant and BP levels [18].

The ET-1 induces multiple effects on vascular tone by binding to two kinds of receptors on endothelial or smooth muscle cells. The ET-A receptors are highly expressed in vascular smooth muscle cells and appear to be the major receptor subtype causing vasoconstriction in human arteries. The ET-B receptors are expressed on both vascular smooth muscle and endothelial cells. The ET-B receptors on endothelial cells mediate vasodilation by releasing NO and prostacyclin and they in turn inhibit ET converting enzyme-1 (ECE-1) expression in endothelial cells and play an important role in ET-1 clearance $[42,43]$. The infusion of ET-1 into intact rats caused transient hypotension related to an increase in the production of endothelium-derived relaxing factor and prostacyclin and their release from vascular endothelial cells $[44,45]$. All this evidence suggested that, in addition to endothelial integrity, the balance between the distribution of ET-A and ET-B receptors may determine the ET-1-dependent regulation of vascular tone. Investigations of the association between another EDN1 polymorphism (Lys198Asn) and BP levels have also produced inconsistent results [46-48]. Clearly, further investigations into the association of the vascular endothelin system with $\mathrm{BP}$ regulation are needed. 
Our study had several strengths that included the consistent results found in both hypertensive patients and normotensive subjects for the association of the $3 \mathrm{~A} / 4 \mathrm{~A}$ polymorphism with $\mathrm{OH}$ and orthostatic BP changes, and the exclusion of any antihypertensive drug effect because only untreated hypertensive patients were enrolled. A limitation of our study was that the plasma or urine levels of ET-1 were not measured. Previous studies $[13-15,49]$ have shown that ETs are autocrine/ paracrine agents rather than circulating hormones, and plasma levels of ETs have been found to be poorly correlated with the hypertensive state. Another limitation of the present study was the focus on only one functional polymorphism of the ET-1 gene. Further research is needed to investigate the association between $\mathrm{OH}$ and other polymorphisms of the genes that encode the vascular endothelin system components (ET-1, and the ET-A and ET-B receptors).

In conclusion, we found no evidence that the insertion variant in the 5' UTR of the EDN1 was associated with a genetic predisposition to hypertension and $\mathrm{OH}$ risk. Our data suggested that the role of ET-1 in BP regulation needs to be evaluated further in future studies.

\section{Acknowledgments}

This work was financially supported by a grant from the National Natural Science Foundation of China (Grant No. 30871054) to Dr Xiao-han Fan, and by a grant from the Ministry of Science and Technology of China (Grant No. 2006CB503805) to Dr. Hui Rutai.

\section{References}

1. Yanagisawa M, Kurihara H, Kimura S, et al. A novel potent vasoconstrictor peptide produced by vascular endothelial cells. Nature 1988; 332: 411-5.

2. MacCarthy PA, Grocott-Mason R, Prendergast BD, Shah AM. Contrasting inotropic effects of endogenous endothelin in the normal and failing human heart: studies with an intracoronary ET(A) receptor antagonist. Circulation 2000; 101: 142-7.

3. Galie N, Manes A, Branzi A. The endothelin system in pulmonary arterial hypertension. Cardiovasc Res 2004; 61: 227-37.

4. Arai H, Hori S, Aramori I, Ohkubo H, Nakanishi S. Cloning and expression of a cDNA encoding an endothelin receptor. Nature 1990; 348: 730-2.

5. Sakurai T, Yanagisawa M, Takuwa Y, et al. Cloning of a cDNA encoding a non-isopeptide-selective subtype of the endothelin receptor. Nature 1990; 348: 732-5.

6. Saito Y, Nakao K, Mukoyama M, Imura H. Increased plasma endothelin level in patients with essential hypertension. N Engl J Med 1990; 322: 205.

7. Kurihara $\mathrm{Y}$, Kurihara $\mathrm{H}$, Suzuki $\mathrm{H}$, et al. Elevated blood pressure and craniofacial abnormalities in mice deficient in endothelin-1. Nature 1994; 368: 703-10.
8. Ahn D, Ge Y, Stricklett PK, et al. Collecting duct-specific knockout of endothelin-1 causes hypertension and sodium retention. J Clin Invest 2004; 114: 504-11.

9. Ge Y, Bagnall A, Stricklett PK, Webb D, Kotelevtsev Y, Kohan DE. Combined knockout of collecting duct endothelin A and B receptors causes hypertension and sodium retention. Am J Physiol Renal Physiol 2008; 295: F1635-40.

10. Stewart DJ, Cernacek P, Costello KB, Rouleau JL. Elevated endothelin-1 in heart failure and loss of normal response to postural change. Circulation 1992; 85: 510-7.

11. Kaufmann H, Oribe E, Oliver JA. Plasma endothelin during upright tilt: relevance for orthostatic hypotension? Lancet 1991; 338: 1542-5.

12. White M, Cernacek P, Courtemanche M, et al. Impaired endothelin-1 release in tilt-induced syncope. Am J Cardiol 1998; 81: 460-4.

13. Abassi ZA, Ellahham S, Winaver J, Hoffman A. The intrarenal endothelin system and hypertension. News Physiol Sci 2001; 16: 152-6.

14. Schiffrin EL, Thibault G. Plasma endothelin in human essential hypertension. Am J Hypertens 1991; 4: 303-8.

15. Schneider JG, Tilly N, Hierl T, et al. Elevated plasma endothelin-1 levels in diabetes mellitus. Am J Hypertens 2002; 15: 967-72.

16. Thorin E, Webb DJ. Endothelium-derived endothelin-1. Pflugers Arch 2010; 459: 951-8.

17. Popowski K, Sperker B, Kroemer HK, et al. Functional significance of a hereditary adenine insertion variant in the 5 '-UTR of the endothelin-1 gene. Pharmacogenetics 2003; 13: 445-51.

18. Winker R, Garland EM, Rudiger HW, et al. Influence of an insertion variant in the 5'UTR of the endothelin-1 gene on orthostatic intolerance. Am J Med Sci 2005; 330: 166-71.

19. Stevens PA, Brown MJ. Genetic variability of the ET-1 and the ETA receptor genes in essential hypertension. J Cardiovasc Pharmacol 1995; 26: S9-12.

20. Panoulas VF, Douglas KM, Smith JP, et al. Polymorphisms of the endothelin-1 gene associate with hypertension in patients with rheumatoid arthritis. Endothelium 2008; 15: 203-12.

21. Brown MJ, Sharma P, Stevens PA. Association between diastolic blood pressure and variants of the endothelin-1 and endothelin-2 genes. J Cardiovasc Pharmacol 2000; 35: S41-3.

22. Executive Summary of The Third Report of The National Cholesterol Education Program (NCEP) Expert Panel on Detection, Evaluation, And Treatment of High Blood Cholesterol In Adults (Adult Treatment Panel III). JAMA 2001; 285: 2486-97.

23. Perloff D, Grim C, Flack J, et al. Human blood pressure determination by sphygmomanometry. Circulation 1993; 88: 2460-2470.

24. Consensus statement on the definition of orthostatic hypotension, pure autonomic failure, and multiple system atrophy. The Consensus Committee of the American Autonomic Society and the American Academy of Neurology. Neurology 1996; 46: 1470.

25. Kisanuki YY, Emoto N, Ohuchi T, et al. Low blood pressure in endothelial cell-specific endothelin 1 knockout mice. Hypertension 2010; 56: 121-8.

26. Cardillo C, Campia U, Kilcoyne CM, Bryant MB, Panza JA. Improved endothelium-dependent vasodilation after blockade of endothelin receptors in patients with essential hypertension. Circulation 2002; 105: 452-6. 
27. Vasku A, Tschoplova S, Muzik J, Soucek M, Vacha J. Association of three polymorphisms in the gene coding for endothelin-1 with essential hypertension, overweight and smoking. Exp Clin Cardiol 2002; 7: 201-4.

28. Vasku A, Spinarova L, Goldbergova M, et al. The double heterozygote of two endothelin-1 gene polymorphisms (G8002A and -3A/-4A) is related to big endothelin levels in chronic heart failure. Exp Mol Pathol 2002; 73: 230-3.

29. Lajemi M, Gautier S, Poirier O, et al. Endothelin gene variants and aortic and cardiac structure in never-treated hypertensives. Am J Hypertens 2001; 14: 755-60.

30. Newton-Cheh C, Johnson T, Gateva V, et al. Genome-wide association study identifies eight loci associated with blood pressure. Nat Genet 2009; 41: 666-76.

31. Levy D, Ehret GB, Rice K, et al. Genome-wide association study of blood pressure and hypertension. Nat Genet 2009; 41: 677-87.

32. Rose KM, Tyroler HA, Nardo CJ, et al. Orthostatic hypotension and the incidence of coronary heart disease: the Atherosclerosis Risk in Communities study. Am J Hypertens 2000; 13: 571-8.

33. Rutan GH, Hermanson B, Bild DE, Kittner SJ, LaBaw F, Tell GS. Orthostatic hypotension in older adults. The Cardiovascular Health Study. CHS Collaborative Research Group. Hypertension 1992; 19: 508-19.

34. Shin C, Abbott RD, Lee H, Kim J, Kimm K. Prevalence and correlates of orthostatic hypotension in middle-aged men and women in Korea: the Korean Health and Genome Study. J Hum Hypertens 2004; 18: 717-23.

35. DeStefano AL, Baldwin CT, Burzstyn M, et al. Autosomal dominant orthostatic hypotensive disorder maps to chromosome 18q. Am J Hum Genet 1998; 63: 1425-30.

36. Pankow JS, Rose KM, Oberman A, et al. Possible locus on chromosome $18 \mathrm{q}$ influencing postural systolic blood pressure changes. Hypertension 2000; 36: 471-6.

37. Chen $\mathrm{H}$, Ross CA, Wang $\mathrm{N}$, et al. NEDD4L on human chromosome $18 \mathrm{q} 21$ has multiple forms of transcripts and is a homologue of the mouse Nedd4-2 gene. Eur J Hum Genet 2001; 9: 922-30.

38. Luo F, Wang Y, Wang X, et al. A functional variant of NEDD4L is associated with hypertension, antihypertensive response, and orthostatic hypotension. Hypertension 2009; 54: 796-801.

39. Tabara Y, Kohara K, Miki T. Polymorphisms of genes encoding components of the sympathetic nervous system but not the renin-angiotensin system as risk factors for orthostatic hypotension. J Hypertens 2002; 20: 651-6.

40. Fan XH, Wang YB, Wang $H$, et al. Polymorphisms of angiotensin-converting enzyme (ACE) and ACE2 are not associated with orthostatic blood pressure dysregulation in hypertensive patients. Acta Pharmacol Sin 2009; 30: 1237-44.

41. Sorrentino S, Forleo C, lacoviello M, Guida P, D'Andria V, Favale S. Endothelin system polymorphisms in tilt testinduced vasovagal syncope. Clin Auton Res 2009; 19: 347-54.

42. Fukuroda T, Fujikawa T, Ozaki S, Ishikawa K, Yano M, Nishikibe M. Clearance of circulating endothelin-1 by ETB receptors in rats. Biochem Biophys Res Commun 1994; 199: 1461-5.

43. Brunner F, Doherty AM. Role of ET(B) receptors in local clearance of endothelin-1 in rat heart: studies with the antagonists PD 155080 and BQ-788. FEBS Lett 1996; 396: 238-42.

44. de Nucci G, Thomas R, D'Orleans-Juste P, et al. Pressor effects of circulating endothelin are limited by its removal in the pulmonary circulation and by the release of prostacyclin and endothelium-derived relaxing factor. Proc Natl Acad Sci U S A 1988; 85: 9797-800.

45. D'Amours M, Chbinou N, Beaudoin J, Lebel M, Lariviere R. Increased $\mathrm{ET}-1$ and reduced $\mathrm{ET}(\mathrm{B})$ receptor expression in uremic hypertensive rats. Clin Exp Hypertens 2010; 32: $61-9$

46. Tiret L, Poirier O, Hallet V, et al. The Lys198Asn polymorphism in the endothelin-1 gene is associated with blood pressure in overweight people. Hypertension 1999; 33: 1169-74.

47. Jin JJ, Nakura J, Wu Z, et al. Association of endothelin-1 gene variant with hypertension. Hypertension 2003; 41: 163-7.

48. Asai T, Ohkubo T, Katsuya T, et al. Endothelin-1 gene variant associates with blood pressure in obese Japanese subjects: the Ohasama Study. Hypertension 2001; 38: 1321-4.

49. Vemulapalli S, Chiu PJ, Rivelli M, Foster CJ, Sybertz EJ. Modulation of circulating endothelin levels in hypertension and endotoxemia in rats. J Cardiovasc Pharmacol 1991; 18: 895-903. 